\title{
Drosophila species (Diptera: Drosophilidae) oviposition patterns on fungi: The effect of allospecifics, substrate toughness, ovipositor structure and degree of specialisation
}

\author{
JENNIFER ROUQUETTE and ANDREW JOHN DAVIS* \\ Centre for Biodiversity and Conservation, School of Biology, University of Leeds, Leeds, LS2 9JT UK
}

Key words. Drosophila, fungi, oviposition, ovipositor structure, resource partitioning

\begin{abstract}
To determine if small-scale resource partitioning aids coexistence in fungal breeding Diptera we investigated the avoidance of interspecific larval competition by micro-resource partitioning of the host substrate in several species of Drosophila ovipositing on fungal fruiting bodies. No avoidance was detected and oviposition patterns were unaffected by the presence of allospecifics. There was a general tendency for all species to oviposit preferentially on the cap but no significant differences between species. Egg distribution was not strongly related to the sporophore's resistance to penetration measured by penetrometer and was also uncorrelated with ovipositor structure even though species had concordant suites of ovipositor characteristics with apparent specialists typified by hard and sharp ovipositors. We discuss the significance to species coexistence of the absence of micro-resource partitioning of the host.
\end{abstract}

\section{INTRODUCTION}

Insect species that occur on the same host plant might well be expected to show evidence of resource partitioning (e.g. Jermy, 1984) reducing interspecific competition by feeding in different parts of the individual host plant (Price, 1975; Crawley, 1983). Such a phenomenon might particularly be expected among Diptera breeding in fungi since this guild is particularly diverse. In the British Isles twelve of the 34 species of Drosophila recorded develop in fungi and most of these twelve occur sympatrically (Shorrocks \& Charlesworth, 1980, 1982; Bingley \& Shorrocks, 1995; Law et al., 1997). In consequence, eggs of more than one of these species may well occur in a single fungal sporophore resulting in interspecific competition between the developing larvae as has been demonstrated in nature (Grimaldi \& Jaenike, 1984). There is little evidence that any of the fungal-breeding Drosophila specialise completely on particular species of fungus (Shorrocks, 1975; Grimaldi, 1985; Jaenike \& James, 1991). In consequence, the high degree of species coexistence might be promoted by resource partitioning on a smaller scale, within sporophores, since these are heterogeneous in structure and in toughness. Different species could oviposit in different parts of the fungal body. We therefore tested whether species oviposition patterns were the same when they were ovipositing alone or with allospecifics and we examined whether there was a relationship between oviposition pattern and the toughness of different parts of the sporophore. We also examined whether there were differences between species in the degree to which eggs were inserted into the substrate rather than laid on the surface since insertion might indicate better adaptation to oviposition on fungi.
If there were species specific oviposition patterns on sporophores, each species would have an ovipositor selected to suit the particular character of the sporophore region in which the eggs were laid. Each species would be expected to have ovipositors of different shape, hardness and associated characteristics (cf Kambysalis \& Heed, 1971). We therefore characterised ovipositors and examined the relationship of these characteristics to oviposition patterns.

\section{MATERIALS AND METHODS}

Fly strains and rearing

The flies used were all of wild type and came from strains that had been laboratory reared for only 6-12 months. They were maintained at $20^{\circ} \mathrm{C}$ and $16 \mathrm{~L}: 8 \mathrm{D}$ on a standard laboratory medium (Shorrocks, 1972) with added minced mushroom. Female flies were removed from stock cages under $\mathrm{CO}_{2}$ anaesthesia and kept on medium for $24 \mathrm{~h}$ at $5 / 500 \mathrm{~mm}^{2}$ thereafter to recover before being transferred directly to the test cages.

\section{Oviposition}

Mushrooms (Agaricus bisporus v albida) were used as the oviposition substrate because sporophores of the same size and shape could be obtained easily and consistently. Fungal breeding Drosophila species accept this fungus as a breeding site in the wild and their larvae develop on it easily (Shorrocks \& Wood, 1973; Bingley \& Shorrocks, 1995). The experiments were carried out with single, open, mushrooms of about $14 \mathrm{~g}$ placed vertically in small transparent plastic cages $(100 \times 100 \times$ $130 \mathrm{~mm}$ ) with the stipe supported on a pin held in a sand-filled petri dish. The sand covered the base of the stipe and was kept damp so that the mushroom did not dry out.

We tested the oviposition patterns of D. busckii Coquillet 1901, D. funebris (Fabricius, 1787) or D. phalerata Meigen 1830 , three species that are common members of the fungal breeding guild in the British Isles (Shorrocks \& Wood,

* Corresponding author. Institute of Ecology, Friedrich Schiller University, Dornburgerstrasse 159, 07743 Jena, Germany; e-mail: Andrew.Davis@uni-jena.de. Current affiliation: Institute of Low Temperature Science, Hokkaido University, Sapporo, 06008 19, Japan. 
1973; Shorrocks \& Charlesworth, 1982; Law et al., 1997) and elsewhere (Kimura et al., 1977; Burla et al., 1991). Their larvae potentially compete interspecifically as the different species can be present in the same sporophores at the same time. This is indicated by the emergence of adults of more than one species from sporophores or bait fungi exposed to oviposition for less time than is required for larval development (e.g. Bingley \& Shorrocks, 1995).

In the first series of experiments the oviposition patterns of conspecific flies were determined by releasing two females of the same species into each cage and allowing them to forage and oviposit together in the absence of allospecifics. In the second series the effect of the simultaneous presence of allospecifics was determined by forcing a single $D$. phalerata to forage with either a single $D$. busckii or a single $D$. funebris.

After $48 \mathrm{~h}$ the eggs on each of the mushrooms were counted and their insertion sites classified as being either on the lower, middle or upper third of the stipe, or on the top, side, fringe or gills of the cap (Fig. 1). The eggs of the species can be distinguished from each other by their different numbers of filaments. To determine whether species do penetrate the fungal surface to oviposit we recorded the depth to which the eggs had been inserted into the mushroom by $D$. busckii, D. funebris, $D$. phalerata and also, in a similar separate experiment, by D. subobscura Collin 1936, another common member of the fungal guild (Shorrocks \& Charlesworth, 1982; Driessen et al., 1990).

\section{Substrate toughness}

The toughness of the substrate was measured using a needle penetrometer (tip diameter $0.19 \mathrm{~mm}$ ) attached to a force transducer which gave output in millivolts. Five measurements were taken on the cap, and on the stipe, of five different mushrooms. The analyses were carried out on the raw data because this was normally distributed. The mean toughnesses are, however, expressed as the force applied (in newtons) and the stress it represents (newtons $\mathrm{m}^{-2}$ ).

\section{Ovipositor structure and specialisation}

We characterised the ovipositors of five species frequently reared from fungi in Europe on the basis of four features potentially important in determining the ovipositors' ability to penetrate substrates. Fly species adapted to oviposit in tough substrates would be expected to show concordant suites of ovipositor characterisitics; e.g. to have both harder and more strongly toothed ovipositors.

The more sclerotised, and thus presumably the harder, the ovipositor plates the darker they are. Ovipositor hardness of the four species $D$. busckii, D. funebris, D. phalerata and D. subobscura, and for the fungal-breeding species D. kuntzei Duda 1924 (Shorrocks \& Wood, 1973; Driessen et al., 1990) was therefore categorised by ranking ovipositor colour on a five point scale from dark brown to transparent off-white. The length of the ovipositor, the number of apical teeth and sharpness (the angle between the ovipositor's dorsal and ventral edges) were measured on 10 individuals of each species. The means of these measures for each species were also ranked.

The degree to which each species specialises on fungal breeding was derived from rearing records in the general literature and in our own field sampling of the species used.

\section{RESULTS}

\section{Oviposition}

Drosophila busckii and D. phalerata both laid a larger mean number of eggs on the A. bisporus than did D. funebris (Table 1). To accommodate these differences in spe-

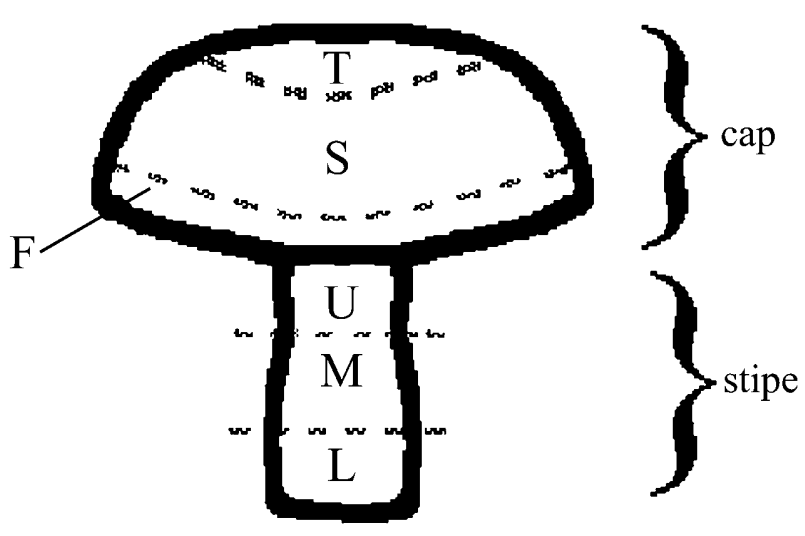

Fig. 1. Division of an Agaricus bisporus sporophore into cap and stipe and into the regions: $\mathrm{T}$ - cap top; $\mathrm{S}$ - cap side; F - cap fringe; $\mathrm{U}$ - upper third of stipe; $\mathrm{M}$ - middle third of stipe; $\mathrm{L}-$ lower third of stipe.

cific fecundity the subsequent analyses were carried out on the proportion of eggs laid on each region or, to control statistically for the different areas of each region, on the region specific density (proportion/area of region). Eggs were found on the gills of only one mushroom and the gills were therefore omitted from the analyses.

There were no significant differences between species in the region specific density of eggs (Friedman $F_{r}=8.71$, $\mathrm{df}=5,0.10<\mathrm{p}<0.20$ ). However, in all three species the distribution of eggs between the six regions was significantly different from that expected if each region received eggs in proportion to its area (Table 1). For D. busckii and $D$. funebris the maximum deviation from expected was in the upper region of the stipe but for $D$. phalerata it was in the side of the cap. There were also significant dif-

TABle 1. Mean proportions of all eggs laid on different regions of Agaricus bisporus sporophores by three Drosophila species with the number of sporophores used and the mean number of eggs per female. For all three species the proportions of eggs laid in each of the six regions of the sporophore are significantly different from those expected if numbers of eggs laid was a simple function of area since $D_{\max }$ for Kolmogorov Smirnov 1-sample tests are significant at $\mathrm{p}<0.01$. The proportion of eggs laid in the cap as a whole was also significantly greater than expected on the basis of area since all $\chi^{2}$ values are significant at $\mathrm{df}=1, \mathrm{p}<<0.001$.

\begin{tabular}{lccc}
\hline & $\begin{array}{c}\text { Drosophila } \\
\text { busckii }\end{array}$ & $\begin{array}{c}\text { Drosophila } \\
\text { funebris }\end{array}$ & $\begin{array}{c}\text { Drosophila } \\
\text { phalerata }\end{array}$ \\
\hline region & & & \\
cap top & 0.5 & 1.4 & 8.1 \\
cap side & 21.3 & 41.1 & 56.5 \\
cap fringe & 0.5 & 4.3 & 8.3 \\
stipe upper & 10.2 & 12.9 & 2.9 \\
stipe middle & 51.2 & 40.0 & 14.9 \\
stipe lower & 16.2 & 0.0 & 9.3 \\
number of mushrooms & 8 & 8 & 17 \\
mean eggs/fly & 12.3 & 4.4 & 11.0 \\
KS D & 0.605 & 0.353 & 0.156 \\
Chi-squared $\chi^{2}$ & 492.3 & 60.3 & 24.1 \\
\hline
\end{tabular}


TABLE 2. Mean proportions of all eggs laid on different regions of Agaricus bisporus sporophores by three Drosophila species when foraging in the presence of allospecifics. None of the $\mathrm{D}_{\max }$ values for Kolmogorov Smirnov 2-sample tests of the distribution of eggs when foraging alone and when foraging with allospecifics was significant at $\mathrm{p}<0.05$.

\begin{tabular}{lcccc}
\hline & $\begin{array}{c}\text { busckii } \\
\text { \& phalerata }\end{array}$ & $\begin{array}{c}\text { phalerata } \\
\text { \& busckii }\end{array}$ & $\begin{array}{c}\text { funebris } \\
\text { \& phalerata }\end{array}$ & $\begin{array}{c}\text { phalerata } \\
\text { \& funebris }\end{array}$ \\
\hline region & & & & \\
cap top & 0.0 & 0.0 & 1.5 & 45.5 \\
cap side & 4.9 & 27.3 & 35.8 & 18.2 \\
cap fringe & 0.0 & 0.0 & 59.7 & 6.8 \\
stipe upper & 7.6 & 18.1 & 0.0 & 6.8 \\
stipe middle & 68.5 & 36.4 & 3.0 & 15.9 \\
stipe lower & 19.0 & 18.2 & 0.0 & 6.8 \\
mean eggs/fly & 25.0 & 15.8 & 11.3 & 14.7 \\
KS D & 7.2 & 16.4 & 19.9 & 14.2 \\
$\mathrm{n}$ & 197 & 375 & 70 & 375 \\
m $_{\max }$ & 175 & 63 & 34 & 44 \\
\hline
\end{tabular}

ferences in the region-specific density of eggs laid on the cap and stipe with more eggs laid on the cap than would be expected from its area (Table 1). These differences overlay and obscured the differences between regions. There were no significant differences between the distribution pattern of eggs laid by a species on its own or when it oviposited simultaneously with a second (Table 2).

There were, however, significant differences between species in the distribution of eggs between insertion categories compared to the proportions expected if deviations between species were due only to chance (Table 3). In particular, over $70 \%$ of $D$. funebris and of $D$. phalerata eggs were fully inserted.

\section{Substrate toughness}

The force transducer readings were significantly different between the cap and the stipe but not between mushrooms (nested anova: mushrooms $\mathrm{F}_{4}=0.83, \mathrm{p}=$ 0.516 ; regions within mushrooms $\mathrm{F}_{5}=6.87, \mathrm{p}<0.001$ ). The force, and the stress it represents, required to break the surface was higher for the stipe $\left(0.306 \mathrm{~N}, 950 \mathrm{kNm}^{-2}\right)$ than for the cap $\left(0.218 \mathrm{~N}, 677 \mathrm{kNm}^{-2}\right)$. There were also

TABLE 3. Proportion of all eggs laid in single species experiments that were not inserted, partially inserted or fully inserted into the mushroom substrate by four species of Drosophila exploiting fungi in Europe. The distribution of eggs between insertion categories is significantly different from the proportions expected if deviations between species were due only to chance (Kolmogorov Smirnov 1-sample test, $\mathrm{n}=726, \mathrm{D}_{\max }=$ $0.074, \mathrm{D}_{\llcorner\llcorner 0.05}=0.050$ ).

\begin{tabular}{lrcc}
\hline & \multicolumn{3}{c}{ Degree of insertion } \\
\cline { 2 - 4 } & none & partial & full \\
\hline D. busckii & 20.3 & 22.3 & 57.4 \\
D. funebris & 22.7 & 4.6 & 72.7 \\
D. phaterata & 3.9 & 25.2 & 70.9 \\
D. subobscura & 23.0 & 38.5 & 38.5 \\
\hline
\end{tabular}

TABLE 4. Rankings of four ovipositor characteristics, and the overall ranking, for five species of Drosophila exploiting fungi in Europe. All four measures of ovipositor structure for the five species examined were highly concordant (Kendal $\mathrm{W}_{5}^{4}=4.175$, $\mathrm{p} \ll<0.01$ ). Overall ranking is the rank of the mean ranking for all four ovipositor characteristics.

\begin{tabular}{lccccc}
\hline & \multicolumn{5}{c}{ Ovipositor characteristics } \\
\cline { 2 - 6 } & $\begin{array}{c}\text { overall } \\
\text { ranking }\end{array}$ & hardness & length & angle & teeth \\
\hline D. busckii & 3.5 & 4 & 3 & 4 & 5 \\
D. funebris & 3.5 & 3 & 4.5 & 3.5 & 3 \\
D. kuntzei & 1 & 2 & 1 & 1 & 1 \\
D. phalerata & 2 & 1 & 2 & 1 & 2 \\
D. subobscura & 2 & 5 & 4.5 & 5 & 4 \\
\hline
\end{tabular}

differences between the separately determined toughness readings for the cap subregions $\left(824,606\right.$ and $477 \mathrm{kNm}^{-2}$ for the top, side and edge respectively). Nevertheless, there were no significant correlations (all $\mathrm{p}>0.01$ ) between substrate toughness and either the number, density or region specific density of eggs except for D. busckii. In this species density was positively, but region-specific density negatively, correlated with toughness to the same degree (Kendal $\mathrm{T}=0.745, \mathrm{z}=2.100, \mathrm{p}=$ 0.0357) as the stipe carried more than the expected number of all eggs, but fewer than the expected number per unit area.

\section{Ovipositor structure and specialisation}

Drosophila kuntzei ranked highest for ovipositor length, sharpness and number of apical teeth and also ranked second for degree of melanisation. Drosophila phalerata ranked highest for melanisation and also ranked highly for the other measures. The lowest ranking species was D. subobscura, and D. busckii and D. funebris had intermediate rankings on all scales (Table 4). All four measures of ovipositor structure for the five species examined were highly concordant (Kendal $\mathrm{W}_{5}^{4}=4.175$, $\mathrm{p}$ $\ll<0.01$ ). Mean ovipositor rankings agreed with rankings produced on the basis of other specific characteristics (Table 5).

Of the five species considered, we assigned the highest degree of specialisation on fungal breeding to D. kuntzei with the remaining species ordered $D$. phalerata $>$ D. busckii $>$ D. funebris $>$ D. subobscura.

\section{DISCUSSION}

Fungal breeding Drosophila species, or at least those studied here, distribute their eggs in similar ways over A. bisporus sporophores. All three species had an overall preference for the cap despite D. phalerata and, particularly, D. busckii, also favouring the upper stipe. In similar experiments Shorrocks \& Wood (1973) also detected no difference between the egg distributions of $D$. phalerata and D. busckii but their preferences cannot be determined because, although both laid more eggs on the stipe, no correction was made for the areas of the two regions. However, on the fungus Phallus impudicus, D. subobscura eggs were laid all over the sporophore whereas 
TABLE 5. Rankings of the specific characteristics of five species of Drosophila exploiting fungi in Europe showing the extent of agreement between the rankings of different characteristics. Ovipositor ranking is the average rank obtained for ovipositor shape and hardness (Table 4), degree of specialism is imputed on the basis of the literature and our field collections, percentage eggs covered (Table 3 ) and the last two columns are rankings derived from the proportion of eggs laid during single species experiments in, respectively, the stipe, the toughest part of the mushroom, and in the toughest part of the cap, the top (Table 1).

\begin{tabular}{lccccc}
\hline & \multicolumn{5}{c}{ Specific characteristics } \\
\cline { 2 - 6 } & $\begin{array}{c}\text { ovipositor } \\
\text { ranking }\end{array}$ & $\begin{array}{c}\text { degree } \\
\text { specialism }\end{array}$ & $\begin{array}{c}\% \text { eggs } \\
\text { covered }\end{array}$ & $\begin{array}{c}\% \text { eggs } \\
\text { in stipe }\end{array}$ & $\begin{array}{c}\% \text { eggs } \\
\text { in cap top }\end{array}$ \\
\hline D. busckii & 3.5 & 3 & 3 & 1 & 3 \\
D. funebris & 3.5 & 4 & 1 & 2 & 2 \\
D. kuntzei & 1 & 1 & & & \\
D. phalerata & 2 & 2 & 2 & 3 & 1 \\
D. subobscura & 5 & 5 & 4 & & \\
\hline
\end{tabular}

those of $D$. phalerata were confined to the peridium and the lower stipe enclosed by it (Shorrocks \& Charlesworth, 1982). Phallus impudicus is atypical, however, since the peridium contains a gelatinous substance quite unlike anything found in other species of fungi. Thus there is little evidence for evolved consistent specific differences in egg distribution that would lower interspecific larval competition. This is unlike the situation for insects feeding in plants (Jermy, 1984) or for the flowerbreeding drosophilid genus Colocasiomyia (Yafuso, 1994) where each species of plant is shared by two species of fly each of which consistently oviposit in different parts of the flower. Neither did females reduce interspecific larval competition by changing oviposition patterns in the presence of allospecifics although our study did not address the possibility that females may change oviposition sites in response to pre-existing allospecific eggs. There was also no tendency in our two-species experiments for females to oviposit together although it might be adaptive at the low densities we used (Wertheim et al., 2002). Such facilitative effects are disputed, however (Hoffmeister \& Rohlfs, 2001), but similar experiments at higher female densities would be of interest.

Our evidence suggests that within-sporophore resource partitioning through species-specific patterns of egg distribution is unlikely. Differential egg distributions might not evolve in Drosophila because, since, unlike insects developing in plants, the larvae often exhaust all the food in a single sporophore (Grimaldi \& Jaenike, 1984), they would eventually compete wherever the eggs had been laid originally.

Within-sporophore patterns of oviposition are therefore more likely to be innate responses to sporophore structure rather than labile behavioural responses. However, except in D. busckii, there is no response to substrate toughness even though the ovipositors of each species show concordant suites of characters. One possible reason for this is that egg insertion is not common as only $D$. funebris and $D$. phalerata often fully insert their eggs. If eggs are not inserted substrate toughness can have no effect on oviposition. A further possibility is that the difficulty of laying an egg into fungal tissue may be inadequately represented by the penetrometer measurements we made. Drosophila females do not insert eggs by simply pushing in the ovipositor but actively excavate a hole in the substrate. The concordant ovipositor characteristics might therefore be adaptations to the resistances of different parts of the sporophore to excavation and we measured resistance to penetration not to excavation. The disjunction between substrate toughness and ovipositor characteristics might also arise because ovipositor characteristics are determined by phylogeny rather than by adaptation. Drosophila kuntzei and D. phalerata belong to the same quinaria-species group and the close similarity of their ovipositors may be a simple consequence of this relatedness. Each of the other species tested comes from a different species group within the Drosophila genus and therefore their individual characteristics might merely represent the characteristics of the species group to which they belong. Our experimental design does not allow the separation of adaptive and phylogenetic characteristics (cf. Harvey \& Pagel, 1991). None of these reasons excludes the additional possibility that the lack of a relationship between egg distribution and substrate toughness within sporophores and the lack of links between egg distribution and ovipositor characteristics may be more fundamentally due to the degrees of specialization on fungi shown by each species. None of the species tested here are confined to fungi in the wild (Offenberger \& Klarenberg, 1992; Law et al., 1997) and so the other substrate types exploited may condition ovipositor characteristics. Specialist species can evolve specialist ovipositors suited to a particular substrate but generalists, ovipositing in substrates with very varied characteristics, cannot. This relationship appears to be present among the species we examined but many more, phylogenetically independent, species would have to be tested to confirm it.

The lack of overt micro-resource partitioning in the fungal feeding Drosophila we examined confirms the impression that Drosophila communities are not structured by competitive resource partitioning at any level (Shorrocks et al., 1984; Shorrocks \& Sevenster, 1995; Wertheim et al., 2000).

ACKNOWLEDGEMENTS. We thank our colleagues in the Biomechanics group at Leeds for the loan of the force transducer and advice on its use. AJD was supported by BBSRC grant 24 GER00620 to Professors JH Lawton and B Shorrocks, and a DAAD fellowship in Jena, Germany.

\section{REFERENCES}

Bingley M. \& Shorrocks B. 1995: Fungal-breeding Drosophila (Diptera, Drosophilidae): an experimental survey using Agaricus bisporus. Entomologist 114: 40-49.

BuRla H., BÄCHLI G. \& Huber H. 1991: Drosophila reared from the stinkhorn, Phallus impudicus, near Zürich, Switzerland. Zt. Zool. Syst. Evol. Forsch. 29: 97-107.

Crawley M.J. 1983: Herbivory: the Dynamics of Animal-Plant Interactions. Blackwell, Oxford, UK, 437pp. 
Driessen G., Hemerik L. \& van Alphen J.J.M. 1990: Drosophila species, breeding in the stinkhorn (Phallus impudicus Pers.) and their larval parasitoids. Neth. J. Zool. 40: 409-427.

GRIMALDI D. 1985: Niche separation and competitive coexistence in mycophagous Drosophila (Diptera: Drosophilidae). Proc. Entomol. Soc. Wash. 87: 498-511.

Grimaldi D. \& JaEnTKE J. 1984: Competition in natural populations of mycophagous Drosophila. Ecology 65: $1115-1120$.

HaRveY P.H. \& PAGEL M.D. 1991: The Comparative Method in Evolutionary Biology. Oxford University Press, Oxford, UK, $239 \mathrm{pp}$.

HofFMeISTER T.S. \& RoHLFS M. 2001: Aggregative egg distributions may promote species co-existence - but why do they exist? Evol. Ecol. Res. 3: 37-50.

JAENIKE J. \& JAMES A.C. 1991: Aggregation and the coexistence of mycophagous Drosophila. J. Anim. Ecol. 60: 913-928.

JERMY T. 1984: Evolution of insect/host plant relationships. Amer. Nat. 124: 609-630.

Kambysalis M.P. \& Heed W.B. 1971: Studies of oogenesis in natural populations of Drosophilidae. I. Relation of ovarian development and ecological habitats of the Hawaiian species. Amer. Nat. 105: 31-49.

Kimura M.T., Toda M.J., Beppu K. \& Watabe H. 1977: Breeding sites of drosophilid flies in and near Sapporo, northern Japan, with supplementary notes on adult feeding habits. Kontyû, Tolyo 45: 571-582.

Law G.R., Parslow R.C., Davis A.J. \& JENKInson L.S. 1997: Drosophilidae exploiting decaying herbage in a Scottish wetland habitat. Entomologist 116: 104-115.

Offenberger M. \& Klarenberg A.J. 1992: Attractiveness and exploitation of decaying herbage by Drosophila in temperate woodland. Oecologia 92: 183-187.

Price P.W. 1975: Insect Ecology. John Wiley \& Sons, New York, NY, USA, $524 \mathrm{pp}$.
SHORRocks B. 1972: Invertebrate Types Drosophila. Ginn, London, UK, $144 \mathrm{pp}$.

Shorrocks B. 1975: The distribution and abundance of woodland species of British Drosophila (Diptera: Drosophilidae). $J$. Anim. Ecol. 44: 851-864.

Shorrocks B. \& Charlesworth P. 1980: The distribution and abundance of the British fungal-breeding Drosophila. Ecol. Entomol. 5: 61-78.

Shorrocks B. \& Charlesworth P. 1982: A field study of the association between the stinkhorn Phallus impudicus Pers. and the British fungal-breeding Drosophila. Biol. J. Linn. Soc. 17: 307-318.

Shorrocks B., Rosewell J., Edwards K. \& Atkinson W. 1984: Interspecific competition is not a major organizing force in many insect communities. Nature 310: 310-312.

Shorrocks B. \& Sevenster J.G. 1995: Explaining local species diversity. Proc. Roy. Soc. Lond. Ser. B. 260: 305-309.

SHORROCKS B. \& WOOD A.M. 1973: A preliminary note on the fungus-feeding species of Drosophila. J. Nat. Hist. 7: 551-556.

Wertheim B., Marchais J., Vet L.E.M. \& Dicke M. 2002: Allee effect in larval resource exploitation in Drosophila: an interaction among density of adults, larvae, and micro-organisms. Ecol. Entomol. 27: 608-617.

Wertheim B., Sevenster J.G., Eus I.E.M. \& van Alphen J.J.M. 2000: Species diversity in a mycophagous insect community: the case of spatial aggregation vs. resource partitioning. $J$. Anim. Ecol. 69: 335-351.

YAFUSO M. 1994: Life history traits related to resource partitioning between synhospitalic species of Colocasiomyia (Diptera: Drosophilidae) breeding in inflorescences of Alocasia odora (Araceae). Ecol. Entomol. 19: 65-73.

Received July 23, 2002; revised November 22, 2002; accepted January 20, 2003 